\title{
Pregabalin for the treatment of generalized anxiety disorder: an update
}

\author{
This article was published in the following Dove Press journal: \\ Neuropsychiatric Disease and Treatment \\ 25 June 2013 \\ Number of times this article has been viewed
}

\author{
David S Baldwin ${ }^{1-3}$ \\ Khalil Ajel ${ }^{3}$ \\ Vasilios G Masdrakis ${ }^{4}$ \\ Magda Nowak' \\ Rizwan Rafiq ${ }^{3}$ \\ 'Clinical and Experimental Sciences \\ Academic Unit, Faculty of Medicine, \\ University of Southampton, \\ Southampton, UK; ${ }^{2}$ Department \\ of Psychiatry and Mental Health, \\ University of Cape Town, Cape Town, \\ South Africa; ${ }^{3}$ Southern Health NHS \\ Foundation Trust, Southampton, UK; \\ ${ }^{4}$ First Department of Psychiatry, \\ Eginition Hospital, Athens University \\ Medical School, Athens, Greece
}

\begin{abstract}
A previous review summarized what was then known about the potential role of pregabalin in the treatment of patients with generalized anxiety disorder (GAD): this review provides an update on its pharmacological properties and presumed mechanism of action, the liability for abuse, and efficacy and tolerability in patients with GAD. Pregabalin has a similar molecular structure to the inhibitory neurotransmitter gamma amino butyric acid (GABA) but its mechanism of action does not appear to be mediated through effects on GABA. Instead, its anxiolytic effects may arise through high-affinity binding to the alpha-2-delta sub-unit of the $\mathrm{P} / \mathrm{Q}$ type voltage-gated calcium channel in "over-excited" presynaptic neurons, thereby reducing the release of excitatory neurotransmitters such as glutamate. The findings of randomized controlled trials and meta-analyses together indicate that pregabalin is efficacious in both acute treatment and relapse prevention in GAD, with some evidence of an early onset of effect, and broad efficacy in reducing the severity of psychological and physical symptoms of anxiety. It also has efficacy as an augmenting agent after non-response to antidepressant treatment in GAD. Continuing vigilance is needed in assessing its potential abuse liability but the tolerability profile of pregabalin may confer some advantages over other pharmacological treatments in the short term for treatment in patients with GAD.
\end{abstract}

Keywords: generalized anxiety disorder, efficacy, tolerability, pregabalin

\section{Clinical features and epidemiology of generalized anxiety disorder}

Generalized anxiety disorder (GAD) is characterized by excessive and inappropriate worrying that is persistent (lasting more than a few months) and not restricted to particular circumstances. Patients have physical anxiety symptoms and key psychological symptoms, including restlessness, difficulty concentrating, irritability, muscle tension, and disturbed sleep. Patients with GAD have the same concerns about health, family, relationships, work, and finances as non-anxious controls but have a greater number of worries over minor matters. However, most patients present with other symptoms; many complain of poor sleep and difficulty in relaxation, but recurrent headaches and various aches and pains are also common. Some patients present repeatedly to health professionals, with pressing but long-standing physical symptoms that prove to be "medically unexplained".

GAD is common in community and clinical settings. A review of the findings of epidemiological studies in Europe suggests a 12-month prevalence of $1.7 \%-3.4 \%,{ }^{1}$ and a lifetime prevalence of around $4.3 \%-5.9 \% .^{2}$ It is probably the most common anxiety disorder among the elderly population. ${ }^{1,3} \mathrm{GAD}$ is usually regarded as a chronic illness, 
which fluctuates in severity over time. It typically emerges gradually ${ }^{4}$ and the onset of the full syndromal disorder is later than in other anxiety disorders. Outcome studies in community samples suggest a reasonable prognosis; for example, a 22-year follow up study of individuals meeting criteria for GAD found that less than $20 \%$ had persistent GAD. ${ }^{5}$ However, longitudinal studies in treatment-seeking patients generally suggest a prolonged and fluctuating course of illness. ${ }^{6}$

GAD is one of the more common mental disorders seen in primary medical care, and is associated with increased use of health services. ${ }^{7}$ Comorbidity with major depression or other anxiety disorders is exceedingly common. ${ }^{1}$ GAD and major depression have a similar degree of functional impairment ${ }^{8,9}$ but patients with comorbid major depression and GAD have a more severe and prolonged course of illness and greater impairment. ${ }^{10}$ GAD is also common among patients with "medically unexplained" chronic pain, ${ }^{11}$ chronic physical ill-health, ${ }^{12}$ and excessive worrying, and GAD may worsen the outcome of cardiovascular disease. ${ }^{13}$

\section{Presumed neuropsychobiology of generalized anxiety disorder}

GAD in adult life is associated with an excess of traumatic experiences and undesirable life events during childhood. ${ }^{14}$ Like other anxiety disorders, GAD is associated with behavioral inhibition in childhood, which is the tendency to be timid or shy in novel situations. ${ }^{15}$ GAD shares a common heritability with major depression ${ }^{16}$ and with the personality trait of "neuroticism". ${ }^{17,18}$ The 5-hydroxtryptamine (5-HT; serotonin) transporter gene-linked polymorphic region short/short genotype is more frequent in patients with GAD ${ }^{19}$ and variations in two sub-types of the glutamic acid decarboxylase gene may increase the susceptibility to anxiety disorders, including GAD. ${ }^{20,21}$ However, investigations of potential disturbances in the principal neurotransmitters noradrenaline (norepinephrine), 5-HT, and gamma aminobutyric acid (GABA) in GAD have tended to produce either inconsistent or unreplicated findings.

Hyperventilation is a well-known component of the bodily response to perceived danger, possibly because exhalation of carbon dioxide $\left(\mathrm{CO}_{2}\right)$ induces a respiratory alkalosis which may partly compensate for a metabolic acidosis arising from rising levels of lactate due to increased physical activity. Rebreathing air enriched with $35 \% \mathrm{CO}_{2}$ does not induce panic attacks in patients with $\mathrm{GAD}^{22}$ nor does intravenous infusion of sodium lactate, ${ }^{23}$ contrary to the effects of these challenges in panic disorder. However, inhaling air enriched with $7.5 \% \mathrm{CO}_{2}$ increases subjective and autonomic symptoms both in healthy volunteers and in patients with GAD. ${ }^{24}$ Some treatments that have been found efficacious in GAD (for example paroxetine and lorazepam) can reduce the emergence of anxiety following $\mathrm{CO}_{2}$ inhalation, ${ }^{25}$ though not all evidence is consistent. ${ }^{26}$

A series of investigations has shown that individuals with GAD scan the environment for cues suggesting threat; ${ }^{27}$ develop worrying in an attempt to solve problems; ${ }^{28}$ may use worrying to avoid physical symptoms of anxiety; ${ }^{29}$ find it hard to tolerate uncertainty or ambiguity;"30 and "worry about worrying". ${ }^{31}$ A functional MRI study found evidence of increased anticipatory activity in the dorsal amygdala after cues indicating forthcoming aversive and neutral pictures, suggesting an "overall enhanced anticipatory emotional responsiveness in GAD" (that is, preparing for difficult challenges ahead). ${ }^{32}$ Investigations of the processing of emotional information suggest that GAD is associated with specific biases for mood-congruent information. ${ }^{33}$ Patients with GAD seem prepared to attend to threatening stimuli, and detect threats rapidly and effectively, ${ }^{34}$ but also tend to misinterpret ambiguous information as being indicative of threat. ${ }^{35}$ Intriguingly, these cognitive biases reduce with successful psychological or pharmacological treatment. ${ }^{36,37}$

\section{Current pharmacological treatments for generalized anxiety disorder}

The findings of systematic reviews ${ }^{38,39}$ and the results of randomized placebo-controlled trials of acute treatment of patients with GAD together provide substantial evidence for the efficacy of many antidepressant drugs, including most selective serotonin reuptake inhibitors (SSRI; citalopram, escitalopram, paroxetine, and sertraline) and the serotonin-norepinephrine reuptake inhibitors (SNRI; duloxetine and venlafaxine) and also for imipramine, trazodone, and agomelatine. ${ }^{40}$ Other compounds with efficacy in placebo-controlled acute treatment studies include some benzodiazepines (alprazolam, diazepam, and lorazepam), ${ }^{41}$ buspirone, ${ }^{42}$ some antipsychotic drugs (quetiapine and trifluoperazine) ${ }^{43}$ and the antihistamine hydroxyzine. ${ }^{44}$ Beta-blockers are often used in primary medical care settings to manage physical symptoms of anxiety but placebo-controlled evidence of efficacy in acute treatment of patients with GAD is minimal. ${ }^{45}$ The findings of randomized placebo-controlled relapse-prevention studies in patients who have previously responded to acute treatment of varying lengths reveal a significant advantage for staying on active medication (including agomelatine, duloxetine, escitalopram, paroxetine, quetiapine, venlafaxine, and vortioxetine), when 
compared to switching to placebo, for periods of between 6-18 months. ${ }^{46}$

In Europe and the US, pregabalin is licensed for the treatment of peripheral and central neuropathic pain, and as an adjunctive therapy in patients with focal epileptic seizures with or without secondary generalization. In the US, pregabalin is also licensed for the treatment of fibromyalgia, whereas in Europe there is no license for fibromyalgia but it is licensed for the treatment of GAD, reflecting its proven efficacy in short-term and long-term treatment.

\section{Preclinical properties and presumed mechanism underlying the anxiolytic effects of pregabalin}

Since the previous review, ${ }^{47}$ there have been considerable advances in the understanding of the presumed mechanism of action of pregabalin underlying its anxiolytic effects. Pregabalin is a branched chain amino acid, similar in structure to leucine and GABA. However, it does not appear to bind to the GABA receptor, or to any binding site allosterically linked to GABA, or to the GABA transporter, or to enzymes involved in the synthetic or metabolic pathways of GABA. ${ }^{48}$ It is absorbed rapidly after oral administration and achieves maximal plasma concentrations within 1-hour: absorption is dependent upon active transport with the L-type amino acid transporter 1 (LAT1) and is linear with proportional increases in plasma levels across the dose range. ${ }^{49}$

Pregabalin shows high affinity binding to the Type 1 and Type 2 proteins of the $\alpha_{2} \delta$ subunit of the P/Q type of voltagegated calcium channel. These channels consist of four protein subunits: the $\alpha_{2} \delta$ subunit comprises a $\delta$ protein which anchors the subunit to the plasma membrane, linked by a disulphide bond to the $\alpha_{2}$ protein which contains the pregabalin binding site. The $\alpha_{2} \delta$ subunit is a glycosylphosphatidylinositol (GPI)-anchored protein ${ }^{50}$ linked to a lipid raft membrane microdomain which appears sensitive to the physiological state of the cell. ${ }^{51}$

Standardized receptor-binding assays have shown that pregabalin has no significant binding to a wide range of receptor sites; conversely, a broad range of anxiolytics and antidepressant drugs have no affinity for the $\alpha_{2} \delta-1$ or $\alpha_{2} \delta-2$ calcium channel subunits. ${ }^{52}$ Autoradiography and immunostaining studies indicate that pregabalin is mainly bound to $\alpha_{2} \delta-1$ subunits in the cortex, olfactory bulb, hypothalamus, amygdala, and hippocampus, but to $\alpha_{2} \delta-2$ subunits in the cerebellum. ${ }^{53,54}$

As with other anxiolytic drugs, administration of pregabalin has been shown to attenuate the activation of the left anterior insula and left amygdala in response to emotionally charged visual stimuli in healthy volunteers. ${ }^{55}$ Pregabalin is also efficacious in the treatment of patients with GAD, ${ }^{56}$ and social anxiety disorder. ${ }^{57}$ These anxiolytic effects of pregabalin are presumed to be mediated through its actions on the $\alpha_{2} \delta-1$ subunit, which leads to reductions in the availability and effects of excitatory neurotransmitters, including glutamate. High-affinity $\alpha_{2} \delta$ ligands exert potent effects in animal models of anxiety; ${ }^{58}$ pregabalin has no anxiolytic-like effects in transgenic mice with specific point mutations in the voltage-gated calcium channel $\alpha_{2} \delta$ Type 1 protein, whereas anxiolytic-like effects are preserved in mice with a point mutation in the $\alpha_{2} \delta-2$ protein. ${ }^{59}$ A range of studies have indicated that through its effects on calcium channels, pregabalin administration reduces the release of glutamate; ${ }^{48}$ furthermore, pregabalin administration may reduce the synthesis of excitatory synapses ${ }^{60}$ and may block the trafficking of new voltage-gated calcium channels to the cell surface. ${ }^{61}$

\section{Evidence base for pregabalin in the treatment of GAD}

Our previous review noted that it was not possible to make definitive statements about the potential role of pregabalin in the overall management of patients with GAD as no placebocontrolled trial with an SSRI as active comparator had been published, the effect of pregabalin on depressive symptoms in patients with GAD was not established, little was known about its longterm tolerability and patient acceptability, and no data was available regarding its use as a second-line treatment in patients who had not responded to previous interventions. $^{47}$

The randomized double-blind placebo-controlled evidence base supporting the use of pregabalin in GAD has steadily expanded, and currently comprises six short term (4-6 week) fixed-dose studies; ${ }^{62-67}$ two short-term (8-week) flexible-dose studies, one in elderly patients, ${ }^{68}$ the other in younger patients; ${ }^{69}$ a single long-term (6-month) fixed dose relapse prevention study; ${ }^{70}$ and a short-term (8-week) flexible-dose study in patients who had not responded to previous treatment with either an SSRI or SNRI antidepressant (Table 1). ${ }^{71}$

Taken together, these studies demonstrate that pregabalin is efficacious in both acute treatment and relapse prevention. Its relative efficacy in acute treatment when compared to other medications is not firmly established, though an analysis of randomized controlled trials which found an overall mean effect size of 0.39 , also found some differences between medication class: pregabalin, 0.50; SNRI, 0.42; 
Table I Randomized placebo-controlled trials of pregabalin in treatment of generalized anxiety disorder

\begin{tabular}{|c|c|c|c|c|}
\hline$\overline{\text { Study }}$ & $\begin{array}{l}\text { Treatment phase } \\
\text { and study sample }\end{array}$ & $\begin{array}{l}\text { Length } \\
\text { (weeks) }\end{array}$ & $\begin{array}{l}\text { Double-blind treatment } \\
\text { arms daily dosage }(n)\end{array}$ & Efficacy? \\
\hline \multirow[t]{4}{*}{ Pande et al ${ }^{67}$} & Acute treatment & 4 & Pregabalin $150 \mathrm{mg}(7 \mathrm{I})$ & No \\
\hline & Adult patients & & Pregabalin $600 \mathrm{mg}(7 \mathrm{I})$ & No \\
\hline & HAMA $\geq 20$ & & Lorazepam 6 mg (70) & No \\
\hline & & & Placebo (70) & - \\
\hline \multirow[t]{4}{*}{ Pande et $\mathrm{a}^{62}$} & Acute treatment & 4 & Pregabalin I50 mg (69) & Yes \\
\hline & Adult patients & & Pregabalin $600 \mathrm{mg}(70)$ & Yes \\
\hline & HAMA $\geq 20$ & & Lorazepam 6 mg (69) & Yes \\
\hline & & & Placebo (68) & - \\
\hline \multirow[t]{4}{*}{ Feltner et al ${ }^{63}$} & Acute treatment & 4 & Pregabalin I50 mg (70) & No \\
\hline & Adult patients & & Pregabalin $600 \mathrm{mg}(66)$ & Yes \\
\hline & HAMA $\geq 20$ & & Lorazepam 6 mg (68) & Yes \\
\hline & & & Placebo (67) & - \\
\hline \multirow[t]{5}{*}{ Rickels et al ${ }^{64}$} & Acute treatment & 4 & Pregabalin 300 mg (91) & Yes \\
\hline & Adult patients & & Pregabalin $450 \mathrm{mg}(90)$ & Yes \\
\hline & HAMA $\geq 20$ & & Pregabalin 600 mg (89) & Yes \\
\hline & & & Alprazolam I.5 mg (93) & Yes \\
\hline & & & Placebo (91) & - \\
\hline \multirow[t]{4}{*}{ Pohl et al ${ }^{65}$} & Acute treatment & 6 & Pregabalin 200 mg (78) & Yes \\
\hline & Adult patients & & Pregabalin $400 \mathrm{mg}(89)$ & Yes \\
\hline & HAMA $\geq 20$ & & Pregabalin $450 \mathrm{mg}(88)$ & Yes \\
\hline & & & Placebo (86) & - \\
\hline Montgomery & Acute treatment & 6 & Pregabalin 400 mg (97) & Yes \\
\hline \multirow[t]{3}{*}{ et $\mathrm{al}^{66}$} & Adult patients & & Pregabalin $600 \mathrm{mg}(110)$ & Yes \\
\hline & HAMA $\geq 20$ & & Venlafaxine $75 \mathrm{mg}(\mathrm{I} / 3)$ & Yes \\
\hline & & & Placebo (I0I) & - \\
\hline Montgomery & Acute treatment & 8 & Pregabalin I50-600 mg (I77) & Yes \\
\hline \multirow[t]{2}{*}{ et $\left.a\right|^{68}$} & Elderly patients (65+ years) & & Placebo (96) & - \\
\hline & HAMA $\geq 20$ & & & \\
\hline \multirow[t]{3}{*}{ Kasper et al ${ }^{69}$} & Acute treatment & 8 & Pregabalin $300-600 \mathrm{mg}(121)$ & Yes \\
\hline & Adult patients & & Venlafaxine $75-225 \mathrm{mg}(125)$ & No \\
\hline & HAMA $\geq 20$ & & Placebo (128) & - \\
\hline \multirow[t]{2}{*}{ Feltner et $\mathrm{al}^{70}$} & Relapse prevention & 26 & Pregabalin $450 \mathrm{mg}(168)$ & Yes \\
\hline & Adult patients & & Placebo (I70) & - \\
\hline \multirow[t]{2}{*}{ Rickels et al ${ }^{71}$} & Treatment resistant & 8 & SSRI/SNRI + pregabalin I50-600 mg (I80) & Yes \\
\hline & Adult patients & & SSRI/SNRI + placebo (I76) & - \\
\hline
\end{tabular}

Abbreviations: HAMA, Hamilton Scale for Anxiety; SSRI selective serotonin reuptake inhibitor; SNRI, serotonin-noradrenaline reuptake inhibitor.

benzodiazepines, 0.38; SSRI, 0.36; and buspirone, $0.17 .{ }^{72}$ The relative efficacy of pregabalin and antidepressant drugs in preventing relapse in patients with GAD, when compared to antidepressant drugs, ${ }^{73}$ is uncertain.

There have been few studies of the further management of patients with GAD who had not responded to first-line interventions. The findings of small randomized placebocontrolled augmentation studies suggest that augmentation of antidepressants with antipsychotic drugs (olanzapine, quetiapine, and risperidone) may be beneficial, ${ }^{7-76}$ though the evidence for quetiapine augmentation is inconsistent ${ }^{77}$ and uncertain for ziprasidone augmentation. ${ }^{78}$ However, the findings of a recent large randomized placebocontrolled augmentation study demonstrate that the addition of pregabalin to SSRI or SNRI antidepressant drugs is superior to continued treatment with antidepressants alone. $^{71}$

\section{Onset of effect and dose-response relationships}

An early onset of effect in reducing anxiety symptoms is considered beneficial in treating patients with anxiety disorders, but the findings of randomized controlled trials tend to indicate that a few weeks pass before antidepressants are superior to placebo. ${ }^{40}$ Pregabalin has been found superior to placebo in reducing anxiety in patients prior to undergoing dental or orthopedic procedures, with an onset of effect within a few hours. ${ }^{79,80}$ In GAD, an assessment of the potential early efficacy of pregabalin has not been reported, although a large, placebo-controlled, flexible-dose trial which included 
an assessment of efficacy at day 4 of treatment found that pregabalin was superior to both venlafaxine XL and placebo at day $4 .{ }^{69}$

For many medications, it is uncertain how long treatment should continue in the absence of signs of improvement, before concluding that a response is unlikely. However, the findings of post hoc analyses of data from randomized double-blind placebo-controlled studies with duloxetine ${ }^{81}$ and escitalopram ${ }^{82}$ suggest that response is unlikely if there is no onset of clinical effect within 4 weeks of starting treatment. A post hoc analysis of randomized controlled trial data with pregabalin indicates that an onset of overall clinical effect within the first 2 weeks is associated with a 5.3-fold odds ratio of responding to treatment, whereas only one quarter of patients who show no onset of clinical effect by the second week will have responded to treatment at study endpoint. ${ }^{83}$

Dose-response relationships for antidepressants in the treatment of patients with GAD are not established, and for pregabalin, the evidence is mixed. Meta-analysis of the findings from randomized controlled trials found no evidence for a dose-response curve for daily dosages between 200-600 mg, although a $150 \mathrm{mg}$ daily dosage was associated with a slower onset of efficacy. ${ }^{84}$ However, a dose-response effect was observed when comparing the lowest dose $(150 \mathrm{mg} / \mathrm{d})$ to the $200-600 \mathrm{mg}$ dosing range. For the $150 \mathrm{mg} / \mathrm{d}$ dose of pregabalin, there was a somewhat lower short-term improvement in both the Hamilton Rating Scale for Anxiety (HAM-A) ${ }^{85}$ total score, and in the HAM-A sleep item. ${ }^{84}$ A post hoc analysis of the effects of pregabalin in reducing severity of psychological and physical anxiety symptoms indicates a $150 \mathrm{mg}$ daily dosage may be suboptimal, whereas no dose-response effect was observed within a daily dosage range of between $300-600 \mathrm{mg}{ }^{86}$

\section{Effects of pregabalin in reducing depressive symptoms, somatic symptoms, and sleep disturbance}

Coexisting depressive symptoms and comorbid depressive disorders are common in patients with a primary diagnosis of GAD. Many clinicians choose an antidepressant when treating patients with comorbid conditions, hoping that a single medication will prove effective in reducing both anxiety and depressive symptom severity. In the clinical trial program with pregabalin patients in which those with severe depressive symptoms were excluded from participation, but those with depressive symptoms of mild or moderate intensity were potentially suitable, a post hoc analysis in the subgroup of patients with more severe depressive symptoms (HAM-D $\geq 15$ ) found that pregabalin treatment was effective in reducing depressive symptoms, across the dosing range of 150-600 mg. ${ }^{87}$ Furthermore findings from the flexibledose comparison of pregabalin (300-600 mg/day) and venlafaxine-XL (75-225 $\mathrm{mg}$ /day) indicate that pregabalin treatment was associated with a significantly greater reduction in HAM-D total score, when compared to placebo $(P=0.018){ }^{69}$

Pain and somatic symptoms, some of which can seem "medically unexplained", are common complaints among patients with GAD, and are often the reasons leading to medical consultation. Pregabalin is licensed for the treatment of neuropathic pain and fibromyalgia, itself characterized by often perplexing somatic symptoms, and a post hoc analysis of clinical trial data has found that it is effective in reducing the severity of cardiovascular, respiratory, muscular, and gastrointestinal symptoms in GAD. ${ }^{86}$ Many patients with GAD are also troubled by persistent insomnia and other forms of sleep disturbance. In a pooled analysis of the clinical trial database with pregabalin, in which $54 \%$ of patients reported moderate-to-severe insomnia at baseline, treatment with pregabalin was associated with a significant reduction in sleep disturbance, across the dosing range of 300-600 mg/day. ${ }^{88}$ Pregabalin was found superior to both placebo and venlafaxine XL in reducing sleep disturbance within the context of a double-blind flexible-dose study ${ }^{69,89}$ in younger patients and treatment with pregabalin was associated with a significant improvement in sleep in elderly patients. ${ }^{68,89}$

\section{Tolerability and safety of pregabalin}

In our previous review ${ }^{47}$ we noted that the increased incidence of hemangiosarcoma seen in mice subject to higher exposures to pregabalin was thought to derive from platelet changes (and associated endothelial cell proliferation) that are not present in rats or in humans. Further analysis of genotoxicity, tumor incidence and tumor genetics indicates that pregabalin can act as a single-species (mice), single tumor-type (hemangiosarcoma) non-genotoxic carcinogen. ${ }^{90}$ Knowledge of the mechanism of hemangioma induction has increased, and it is now thought that increased bicarbonate, and dysregulated erythropoiesis, macrophage activation, and increased angiogenic growth factors may all be important. ${ }^{91}$ Pregabalin appears to induce hypoxia and endothelial cell proliferation in a species-specific manner, but these effects can be inhibited by vitamin E, presumably due to its antioxidant and antiangiogenic properties. ${ }^{92}$ Based on an extensive dataset, a recent review concluded that the findings 
seen in mice are not relevant to humans at the clinical dose of pregabalin, and that use of pregabalin does not pose an increased risk for hemangiosarcoma in humans. ${ }^{93}$

The findings of randomized controlled trials indicate that treatment with pregabalin is generally well-tolerated, across the daily dosing range of 150-600 $\mathrm{mg}$. In the clinical trial database the majority of adverse events were recorded as being mild-to-moderate in severity, though dizziness and somnolence were rated as "severe" by more than $2 \%$ of patients. A similar proportion of patients withdrew from further participation due to an adverse event (pregabalin 11.3\%; placebo 9.3\%). ${ }^{94}$ Most adverse events have an onset in the first week of treatment, and tend to have remitted within 3 weeks. Little is known about the relative tolerability of pregabalin when compared to other treatments; however, the adverse event profile of pregabalin differs to that of venlafaxine XL, pregabalin being associated with more prominent dizziness and vertigo, and venlafaxine XL with more prominent nausea, ${ }^{69}$ and a pooled analysis of studies that included a benzodiazepine indicates that treatment with pregabalin is more likely to be associated with dizziness, and benzodiazepine treatment more likely to be associated with somnolence and incoordination. The findings of a more recent mixed treatment comparison suggest that the tolerability of pregabalin in acute treatment is probably better than that of comparator medications. ${ }^{40}$

The potential for weight gain is a common concern among patients undergoing long-term treatment with antidepressant or anxiolytics drugs. In our earlier review ${ }^{47}$ we noted that weight gain of potential clinical significance (ie, more than $7 \%$ increase) was present in $4 \%$ of patients undergoing treatment with pregabalin, compared to $1.4 \%$ of those allocated to placebo. As a recent meta-analysis of the clinical trial database for pregabalin across four clinical areas (mental disorder, drug-resistant partial epilepsy, fibromyalgia, and neuropathic pain) indicates that the adverse event profile is similar in all four areas, ${ }^{95}$ it seems reasonable to examine changes in weight during pregabalin treatment for other conditions. In the clinical trial database of studies in postherpetic neuralgia or neuropathic pain, weight gain was reported in 3.8\%-7.0\% of Western patients but $11.7 \%-13.4 \%$ of Japanese patients, perhaps due to their lower mean body weight; ${ }^{96}$ and in the clinical trial database for studies in fibromyalgia, weight gain was significantly more frequent with pregabalin $(0.97 \%)$ than placebo $(0.22 \%) .{ }^{97}$

Case reports have described the association of pregabalin treatment with the development of peripheral edema, ${ }^{98-101}$ peripheral edema and worsened hepatic function, ${ }^{102}$ and with peripheral edema and pleural effusion. ${ }^{103}$ However, other potentially causative factors were present in all patients. The exact incidence of edema in patients with GAD is uncertain, although it was significantly more frequent with pregabalin $(5.9 \%)$ than with placebo (1.6\%) in the fibromyalgia clinical trial database ${ }^{97}$ and occurs in a similar proportion of patients with fibromyalgia or neuropathic pain..$^{95}$

In our previous review, ${ }^{47}$ we noted that overdoses of pregabalin in approximately 100 patients had not been associated with unexpected adverse events or medically important consequences. A subsequent case report described the development of complete but transient atrioventricular block following pregabalin overdose. ${ }^{104}$ However, a review of 42 cases of pregabalin overdose indicates that serious complications are unusual, ${ }^{105}$ and a case report has described full recovery with general supportive care only, after ingestion of 8.4 grams of pregabalin, which resulted in a serum level of $66.5 \mathrm{mg} / \mathrm{L} .{ }^{106}$

\section{Potential for abuse of and dependence on pregabalin}

Our earlier review ${ }^{47}$ noted that while pre-clinical studies in animal models had indicated that pregabalin had neither a benzodiazepine- or morphine-like discriminative stimulus, and was not self-administered in a sustained manner, some evidence of drug "likeability" had been seen in human recreational drug abusers. ${ }^{107}$ However, pregabalin does not appear to increase the "likeability" of opiate analgesics. ${ }^{108}$ "Euphoria" was an adverse event in clinical trials among $1 \%-10 \%$ of patients, depending on dose, compared to $0.5 \%$ in patients receiving placebo, ${ }^{94}$ which emphasizes the need for careful and continuing evaluation of any potential for abuse. Since entering widespread clinical use, reports of pregabalin abuse have appeared, often involving individuals with a history of abuse of other medications. ${ }^{109-113}$

Discontinuation symptoms were reported after abruptly stopping pregabalin within the randomized controlled trial program; these were more prominent after stopping higher daily doses, ${ }^{63,65}$ but there were significantly fewer withdrawal symptoms after stopping pregabalin than after stopping lorazepam. ${ }^{62}$ However, a number of case reports and case series suggest that pregabalin may be beneficial in facilitating withdrawal from benzodiazepines and related compounds. ${ }^{114-117}$ A switch study in which patients receiving long-term benzodiazepines were randomized to 12 weeks of double-blind treatment with either flexible-dose pregabalin or placebo while the dosage of benzodiazepines was tapered down, followed by a 6-week benzodiazepine-free phase, found that pregabalin was more beneficial (though not significantly 
superior) than placebo in enabling patients to become benzodiazepine-free $(51.4 \%$ versus $37 \%$, respectively; $P=0.284) .{ }^{118}$ In addition, preclinical studies in animal models indicate that pregabalin reduces alcohol consumption and alcohol-seeking behavior, ${ }^{119}$ and reduces the severity of handling-induced seizures in mice withdrawing from alcohol. ${ }^{120}$ The evidence that pregabalin facilitates alcohol withdrawal symptoms and the maintenance of abstinence in detoxified patients is encouraging but inconsistent. ${ }^{121}$

\section{Conclusion}

GAD is a common, distressing, and impairing medical condition that tends to run a chronic or episodic course. A broad range of psychological and pharmacological interventions are available, but many patients do not respond to first-line approaches, and many are troubled by side effects that can limit treatment adherence and increase the risk of relapse. Pregabalin is efficacious in acute treatment and in the prevention of relapse, has comparable efficacy to alternative medications including certain benzodiazepines and the SNRI venlafaxine, and may have tolerability advantages over some comparator treatments. It is efficacious in reducing the severity of psychological and physical symptoms of anxiety, in reducing sleep disturbance, and in reducing the severity of coexisting depressive symptoms, and is also efficacious as a second-line treatment, in patients who have not responded to initial treatment with SSRI or SNRI antidepressants. It has been recommended as a potential first-line treatment in patients with $\mathrm{GAD}^{122}$ and in psychiatric practice is commonly used both as a first-line treatment and as a second-line treatment either on its own or as an augmentation agent. ${ }^{123}$ Because of its beneficial effects in reducing sleep disturbance and somatic symptom severity, it has also been recommended as a first-line treatment for patients with GAD seen in primary care settings. ${ }^{124}$ There have been steady advances in understanding of its properties in animal models, and of the molecular and neuropsychological mechanisms thought to underlie its anxiolytic effects. As with all psychotropic medications, continuing vigilance is needed when assessing the potential for the development of tolerance, dependence, discontinuation symptoms, and abuse.

\section{Disclosure}

The authors report no conflicts of interest in this work.

\section{References}

1. Wittchen HU, Jacobi F, Rehm J, et al. The size and burden of mental disorders and other disorders of the brain in Europe 2010. Eur Neuropsychopharmacol . 2011;21(9):655-679.
2. Wittchen HU, Jacobi F. Size and burden of mental disorders in Europe - a critical review and appraisal of 27 studies. Eur Neuropsychopharmacol. 2005;15(4):357-376.

3. Lenze E. Anxiety disorders in the elderly. In: Stein D, Hollander E, Rothbaum B, editors. Textbook of Anxiety Disorders, 2nd ed. Washington: American Psychiatric Publishing Inc; 2010:651-664.

4. Beesdo K, Knappe S, Pine DS. Anxiety and anxiety disorders in children and adolescents: developmental issues and implications for DSM-V. Psychiat Clin NAm. 2009a;32(3):483-524.

5. Angst J, Gamma A, Baldwin DS, Ajdacic-Gross V, Roessler W. The generalized anxiety spectrum: prevalence, onset, course and outcome. Eur Arch Psy Clin N. 2009;259(1):37-45.

6. Bruce SE, Yonkers KA, Otto MW, et al. Influence of psychiatric comorbidity on recovery and recurrence in generalized anxiety disorder, social phobia, and panic disorder: a 12-year prospective study. Am J Psychiat. 2005;162(6):1179-1187.

7. Wittchen HU, Kessler RC, Beesdo K, Krause P, Hofler M, Hoyer J. Generalized anxiety and depression in primary care: prevalence, recognition, and management. J Clin Psychiat. 2002;63:24-34.

8. Kessler RC, DuPont RL, Berglund P, Wittchen HU. Impairment in pure and comorbid generalized anxiety disorder and major depression at 12 months in two national surveys. Am J Psychiat. 1999;156(12): 1915-1923.

9. Wittchen HU, Carter RM, Pfister H, Montgomery SA, Kessler RC. Disabilities and quality of life in pure and comorbid generalized anxiety disorder and major depression in a national survey. Int Clin Psychopharm. 2000;15(6):319-328.

10. Tyrer P, Seivewright H, Johnson T. The Nottingham Study of Neurotic Disorder: Predictors of 12-year outcome of dysthymic, panic and generalized anxiety disorder. Psychol Med. 2004;34(8): $1385-1394$.

11. Beesdo K, Hoyer J, Jacobi F, Low NCP, Hofler M, Wittchen HU. Association between generalized anxiety levels and pain in a community sample: evidence for diagnostic specificity. J Anxiety Disord. 23(5):684-693.

12. Allgulander C. Morbid anxiety as a risk factor in patients with somatic diseases: a review of recent findings. Mind Brain. 2010;1:1-9.

13. Martens EJ, de Jonge P, Na B, Cohen BE, Lett H, Whooley MA. Scared to Death? Generalized Anxiety Disorder and Cardiovascular Events in Patients With Stable Coronary Heart Disease The Heart and Soul Study. Arch Gen Psychiat. 2010;67(7):750-758.

14. Safren S, Gershuny B, Marzol P, Otto M, Pollack M. History of childhood abuse in panic disorder, social phobia, and generalized anxiety disorder. J Nerv Ment Dis. 2002;190(7):453-456.

15. Rosenbaum J, Biederman J, Bolduc-Murphy E, et al. Behavioral inhibition in childhood: a risk factor for anxiety disorders. Harvard Rev Psychiat. 1993;1(1):2-16.

16. Kendler KS. Major depression and generalised anxiety disorder-Same genes, (partly) different environments - Revisited. Brit J Psychiat. 1996;168:68-75.

17. Hettema JM, Prescott CA, Kendler KS. Genetic and environmental sources of covariation between generalized anxiety disorder and neuroticism. Am J Psychiat. 2004;161(9):1581-1587.

18. Mackintosh MA, Gatz M, Wetherell JL, Pedersen NL. A twin study of lifetime generalized anxiety disorder (GAD) in older adults: genetic and environmental influences shared by neuroticism and GAD. Twin Res Hum Genet. 2006;9(1):30-37.

19. You JS, Hu SY, Chen BL, Zhang HG. Serotonin transporter and tryptophan hydroxylase gene polymorphisms in Chinese patients with generalized anxiety disorder. Psychiatr Gen. 2005;15(1):7-11.

20. Donner J, Sipila T, Ripatti S, et al. Support for involvement of glutamate decarboxylase 1 and neuropeptide y in anxiety susceptibility. Am J Med Genet B. 2012;159B(3):316-327.

21. Unschuld P, Ising $M$, Specht $M$, et al. Polymorphisms in the GAD-2 gene-region are associated with susceptibility for unipolar depression and with a risk factor for anxiety disorders. Am J Med Genet B. 2012;150B(8):1100-1109. 
22. Verburg K, Griez E, Meijer J, Pols H. Discrimination between panic disorder and generalized anxiety disorder by $35 \%$ carbon dioxide challenge. Am J Psychiat. 1995;152(7):1081-1083.

23. Cowley DS, Dager SR, McClellan J, Roybyrne PP, Dunner DL. Response to lactate infusion in generalized anxiety disorder. Biol Psychiatry. 1988;24(4):409-414.

24. Seddon K. Effects of $7.5 \% \mathrm{CO} 2$ challenge in generalized anxiety disorder. J Psychopharmacol. 2011;25(1):43-51.

25. Bailey JE, Kendrick A, Diaper A, Potokar JP, Nutt DJ. A validation of the $7.5 \% \mathrm{CO} 2$ model of GAD using paroxetine and lorazepam in healthy volunteers. $J$ Psychopharmacol. 2007;21:42-49.

26. Diaper A, Osman-Hicks V, Rich A, et al. Evaluation of the effects of venlafaxine and pregabalin on the carbon dioxide inhalation models of Generalised Anxiety Disorder and panic. J Psychopharmacol. 2013;27: 135-145.

27. Beck A, Emery G, Greenberg R. Anxiety Disorders and Phobias: a Cognitive Perspective. New York: Basic Books; 1985.

28. Barlow D. Anxiety and Its Disorders: the Nature and Treatment of Anxiety and Panic. New York: Guilford; 1988.

29. Borkovec T, Alcaine O, Behar E. Avoidance theory of worry and generalized anxiety disorder. In: Heimberg R, Turk C, Mennin D, editors. Generalized Anxiety Disorder: advances in Research and Parctice. New York: Guilford; 2004:77-108.

30. Dugas MJ, Marchand A, Ladouceur R. Further validation of a cognitivebehavioral model of generalized anxiety disorder: diagnostic and symptom specificity. J Anxiety Disord. 2005;19(3):329-343.

31. Wells A, King P. Metacognitive therapy for generalized anxiety disorder: An open trial. J Behav Ther Exp Psy. 2006;37(3):206-212.

32. Nitschke JB, Sarinopoulos I, Oathes DJ, et al. Anticipatory activation in the amygdala and anterior cingulate in generalized anxiety disorder and prediction of treatment response. Am J Psychiat. 2009;166(3):302-310.

33. Coles ME, Turk CL, Heimberg RG. Memory bias for threat in generalized anxiety disorder: the potential importance of stimulus relevance. Cognit Behav Ther. 2007;36(2):65-73.

34. MacLeod C, Mathews A, Tata P. Attentional bias in emotional disorders. J Abnorm Psychol. 1986;95(1):15-20.

35. Mathews A, Richards A, Eysenck M. Interpretation of homophones related to threat in anxiety states. J Abnorm Psychol. 1989;98:31.

36. Mogg K, Bradley BP, Millar N, White J. A follow-up study of cognitive bias in generalized anxiety disorder. Behav Res Ther. 1995;33(8): 927-935.

37. Mogg K, Baldwin DS, Brodrick P, Bradley BP. Effect of short-term SSRI treatment on cognitive bias in generalised anxiety disorder. Psychopharmacology (Berl). 2004;176(3-4):466-470.

38. Baldwin DS, Waldman S, Allgulander C. Evidence-based pharmacological treatment of generalized anxiety disorder. Int $J$ Neuropsychopharmacol. 2011a;14(5):697-710.

39. National Institute for Health and Clinical Excellence. Generalised anxiety disorder and panic disorder (with or without agoraphobia) in adults: Management in primary, secondary and community care. NICE Clinical Guideline 113. Manchester: National Institute for Health and Clinical Excellence; 2011.

40. Baldwin D, Woods R, Lawson R, Taylor D. Efficacy of drug treatments for generalised anxiety disorder: systematic review and meta-analysis. BMJ. 2011b;342:d1199.

41. Martin JLR, Sainz-Pardo M, Furukawa TA, Martin-Sanchez E, Seoane T, Galan C. Benzodiazepines in generalized anxiety disorder: heterogeneity of outcomes based on a systematic review and meta-analysis of clinical trials. J Psychopharmacol. 2007;21(7):774-782.

42. Chessick CA, Allen HA, Thase ME, et al. Azapirones for generalized anxiety disorder [review]. Cochrane Database of Systematic Reviews. 2006;19:CD006115.

43. Lalonde CD, Van Lieshout RJ. Treating generalized anxiety disorder with second generation antipsychotics a systematic review and metaanalysis. J Clin Psychopharmacol. 2011;31(3):326-333.

44. Guaiana G, Barbui C, Cipriani A. Hydroxyzine for generalised anxiety disorder. Cochrane Database of Syst Rev. 2010;8(12):CD006815.
45. Meibach RC, Dunner D, Wilson LG, Ishiki D, Dager SR. Comparative efficacy of propranolol, chlordiazepoxide, and placebo in the treatment of anxiety: a double-blind trial. J Clin Psychiat. 1987;48(9): 355-358.

46. Baldwin DS, Loft H, Florea I. Lu AA21004, a multimodal psychotropic agent, in the prevention of relapse in adult patients with generalized anxiety disorder. Int Clin Psychopharm. 2012;27(4):197-207.

47. Baldwin DS, Ajel K. The role of pregabalin in the treatment of generalized anxiety disorder. Neuropsychiatr Dis Treat. 2007;3(2):185-191.

48. Micó J, Prieto R. Elucidating the mechanism of action of pregabalin: $\alpha(2)$ $\delta$ as a therapeutic target in anxiety. CNS Drugs. 2012;26(8):637-648.

49. Bockbrader HN, Radulovic LL, Posvar EL, et al. Clinical pharmacokinetics of pregabalin in healthy volunteers. J Clin Pharmacol. 2010;50(8):941-950.

50. Davies A, Kadurin I, Alvarez-Laviada A, et al. The alpha(2)delta subunits of voltage-gated calcium channels form GPI-anchored proteins, a posttranslational modification essential for function. Proc Natl Acad Sci U S A. 2010;107(4):1654-1659.

51. Davies A, Hendrich J, Van Minh AT, Wratten J, Douglas L, Dolphin AC. Functional biology of the alpha(2)delta subunits of voltage-gated calcium channels. Trends Pharmacol Sci. 2007;28(5):220-228.

52. Li Z, Taylor CP, Weber M, et al. Pregabalin is a potent and selective ligand for alpha(2)delta-1 and alpha(2)delta-2 calcium channel subunits. Eur J Pharmacol. 2011;667(1-3):80-90.

53. Bian F, Li Z, Offord J, et al. Calcium channel alpha2-delta type 1 subunit is the major binding protein for pregabalin in neocortex, hippocampus, amygdala, and spinal cord: an ex vivo autoradiographic study in alpha2delta type 1 genetically modified mice. Brain Res. 2006;1075:68-80.

54. Taylor CP, Garrido R. Immunostaining of rat brain, spinal cord, sensory neurons and skeletal muscle for calcium channel alpha(2)delta (alpha(2)-delta) type 1 protein. Neuroscience. 2008;155(2): $510-521$

55. Aupperle RL, Ravindran L, Tankersley D, et al. Pregabalin influences insula and amygdala activation during anticipation of emotional images. Neuropsychopharmacol. 2011;36(7):1466-1477.

56. Wensel TM, Powe KW, Cates ME. Pregabalin for the treatment of generalized anxiety disorder. Ann Pharmacother. 2012;46(3): 424-429.

57. Feltner DE, Liu-Dumaw M, Schweizer E, Bielski R. Efficacy of pregabalin in generalized social anxiety disorder: results of a doubleblind, placebo-controlled, fixed-dose study. Int Clin Psychopharm. 2011;26(4):213-220.

58. Belliotti TR, Capiris T, Ekhato IV, et al. Structure-activity relationships of pregabalin and analogues that target the alpha(2)-delta protein. $J$ Med Chem. 2005;48(7):2294-2307.

59. Lotarski SM, Donevan S, El-Kattan A, et al. Anxiolytic-like activity of pregabalin in the vogel conflict test in alpha(2)delta-1 (R217A) and alpha(2)delta-2 (R279A) mouse mutants. $J$ Pharmacol Exp Ther. 2011;338(2):615-621.

60. Eroglu C, Allen NJ, Susman MW, et al. Gabapentin receptor alpha 2 delta-1 is a neuronal thrombospondin receptor responsible for excitatory CNS synaptogenesis. Cell. 2009;139(2):380-392.

61. Field MJ, Cox PJ, Stott E, et al. Identification of the alpha(2)delta-1 subunit of voltage-dependent calcium channels as a molecular target for pain mediating the analgesic actions of pregabalin. Proc Natl Acad Sci U S A. 2006;103(46):17537-17542.

62. Pande AC, Crockatt JG, Feltner DE, et al. Pregabalin in generalized anxiety disorder: a placebo-controlled trial. Am J Psychiat. 2003;160(3): 533-540.

63. Feltner DE, Crockatt JG, Dubovsky SJ, et al. A randomized, doubleblind, placebo-controlled, fixed-dose, multicenter study of pregabalin in patients with generalized anxiety disorder. J Clin Psychopharmacol. 2003;23(3):240-249.

64. Rickels K, Pollack MH, Feltner DE, et al. Pregabalin for treatment of generalized anxiety disorder - A 4-week, multicenter, double-blind, placebo-controlled trial of pregabalin and alprazolam. Arch Gen Psychiat. 2005;62(9):1022-1030. 
65. Pohl RB, Feltner DE, Fieve RR, Pande AC. Efficacy of pregabalin in the treatment of generalized anxiety disorder - Double-blind, placebo-controlled comparison of BID versus TID dosing. J Clin Psychopharmacol. 2005;25(2):151-158.

66. Montgomery SA, Tobias K, Zornberg GL, Kasper S, Pande AC. Efficacy and safety of pregabalin in the treatment of generalized anxiety disorder: a 6-week, multicenter, randomized, double-blind, placebo-controlled comparison of pregabalin and venlafaxine. J Clin Psychiat. 2006;67(5): 771-782.

67. Pande A, Crockatt M, Janney C, Feltner D. Pregabalin treatment of GAD. American Psychiatric Association 153rd Annual Meeting; May 13-18, 2006; Chicago, IL, USA.

68. Montgomery S, Chatamra K, Pauer L, Whalen E, Baldinetti F. Efficacy and safety of pregabalin in elderly people with generalised anxiety disorder. Brit J Psychiat. 2008;193(5):389-394.

69. Kasper S, Herman B, Nivoli G, et al. Efficacy of pregabalin and venlafaxine-XR in generalized anxiety disorder: results of a doubleblind, placebo-controlled 8-week trial. Int Clin Psychopharm. 2009;24(2):87-96.

70. Feltner D, Wittchen H-U, Kavoussi R, Brock J, Baldinetti F, Pande AC. Long-term efficacy of pregabalin in generalized anxiety disorder. Int Clin Psychopharm. 2008;23(1):18-28.

71. Rickels K, Shiovitz TM, Ramey TS, Weaver JJ, Knapp LE, Miceli JJ. Adjunctive therapy with pregabalin in generalized anxiety disorder patients with partial response to SSRI or SNRI treatment. Int Clin Psychopharm. 2012;27(3):142-150.

72. Hidalgo RB, Tupler LA, Davidson JRT. An effect-size analysis of pharmacologic treatments for generalized anxiety disorder. J Psychopharmacol. 2007;21(8):864-872.

73. Donovan MR, Glue P, Kolluri S, Emir B. Comparative efficacy of antidepressants in preventing relapse in anxiety disorders - A metaanalysis. J Affect Disord. 2010;123(1-3):9-16.

74. Brawman-Mintzer O, Knapp RG, Nietert PJ. Adjunctive risperidone in generalized anxiety disorder: a double-blind, placebo-controlled study. J Clin Psychiat . 2005;66(10):1321-1325.

75. Pollack MH, Simon NM, Zalta AK, et al. Olanzapine augmentation of fluoxetine for refractory generalized anxiety disorder: a placebo controlled study. Biol Psychiatry. 2006;59(3):211-215.

76. Altamura AC, Serati M, Buoli M, Dell'Osso B. Augmentative quetiapine in partial/nonresponders with generalized anxiety disorder: a randomized, placebo-controlled study. Int Clin Psychopharm. 2011;26(4):201-205.

77. Simon NM, Connor KM, LeBeau RT, et al. Quetiapine augmentation of paroxetine $\mathrm{CR}$ for the treatment of refractory generalized anxiety disorder: preliminary findings. Psychopharmacology (Berl). 2008; 197(4):675-681.

78. Lohoff FW, Etemad B, Mandos LA, Gallop R, Rickels K. Ziprasidone treatment of refractory generalized anxiety disorder a placebocontrolled, double-blind study. J Clin Psychopharmacol. 2010; 30(2):185-189.

79. Nutt D, Mandel F, Baldinetti F. Early onset anxiolytic efficacy after a single dose of pregabalin: double-blind, placebo- and active-comparator controlled evaluation using a dental anxiety model. J Psychopharmacol. 2009;23(8):867-873.

80. Gonano C, Latzke D, Sabeti-AschrafM, Kettner SC, ChiariA, Gustorff B The anxiolytic effect of pregabalin in outpatients undergoing minor orthopaedic surgery. J Psychopharmacol. 2011;25(2): 249-253.

81. Pollack MH, Kornstein SG, Spann ME, Crits-Christoph P, Raskin J, Russell JM. Early improvement during duloxetine treatment of generalized anxiety disorder predicts response and remission at endpoint. J Psychiatr Res. 2008;42(14):1176-1184.

82. Baldwin DS, Stein DJ, Dolberg OT, Bandelow B. How long should a trial of escitalopram treatment be in patients with major depressive disorder, generalised anxiety disorder or social anxiety disorder? An exploration of the randomised controlled trial database. Hum Psychopharmacol. 2009;24(4):269-275.
83. Baldwin DS, Schweizer E, Xu Y, Lyndon G. Does early improvement predict endpoint response in patients with generalized anxiety disorder (GAD) treated with pregabalin or venlafaxine XR? Eur Neuropsychopharmacol. 2012;22(2):137-142.

84. Bech P. Dose-response relationship of pregabalin in patients with generalized anxiety disorder. A pooled analysis of four placebocontrolled trials. Pharmacopsychiatry. 2007;40(4):163-168.

85. Hamilton $\mathrm{M}$. The assessment of anxiety states by rating. $\mathrm{Br} \mathrm{J} \mathrm{Med}$ Psychol. 1959;32(1):50-55.

86. Lydiard RB, Rickels K, Herman B, Feltner DE. Comparative efficacy of pregabalin and benzodiazepines in treating the psychic and somatic symptoms of generalized anxiety disorder. Int $J$ Neuropsychopharmacol. 2010;13(2):229-241.

87. Stein DJ, Baldwin DS, Baldinetti F, Mandel F. Efficacy of pregabalin in depressive symptoms associated with generalized anxiety disorder: a pooled analysis of 6 studies. Eur Neuropsychopharmacol. 2008;18(6):422-430

88. Montgomery SA, Herman BK, Schweizer E, Mandel FS. The efficacy of pregabalin and benzodiazepines in generalized anxiety disorder presenting with high levels of insomnia. Int Clin Psychopharm. 2009;24(4):214-222.

89. Holsboer-Trachsler E, Prieto R. Effects of pregabalin on sleep in generalized anxiety disorder. Int J Neuropsychopharmacol. 2012;25: $1-12$.

90. Pegg D, Bleavins M, Herman J, et al. Hemangiosarcoma in mice administered pregabalin: analysis of genotoxicity, tumor incidence, and tumor genetics. Toxicol Sci. 2012;128(1):9-21.

91. Criswell KA, Wojcinski Z, Pegg D, et al. Key components of the mode of action for hemangiosarcoma induction in pregabalin-treated mice: evidence of increased bicarbonate, dysregulated erythropoiesis, macrophage activation, and increased angiogenic growth factors in mice but not in rats. Toxicol Sci. 2012;128(1):22-41.

92. Criswell KA, Cook JC, Morse D, et al. Pregabalin induces hepatic hypoxia and increases endothelial cell proliferation in mice, a process inhibited by dietary vitamin E supplementation. Toxicol Sci. 2012; 128(1):42-56.

93. Criswell KA, Cook JC, Wojcinski Z, et al. Mode of action associated with development of hemangiosarcoma in mice given pregabalin and assessment of human relevance. Toxicol Sci. 2012;128(1): 57-71.

94. European Medicines Agency. Lyrica (pregabalin). 2013. Available from:www.emea.europa.eu/humandocs/Humans/EPAR/lyrica/lyrica. htm. Accessed March 20, 2013.

95. Zaccara G, Perucca P, Gangemi PF. The adverse event profile of pregabalin across different disorders: a meta-analysis. European Journal of Clinical Pharmacology. 2012;68(6):903-912.

96. Ogawa S, Satoh J, Arakawa A, Yoshiyama T, Suzuki M. Pregabalin treatment for peripheral neuropathic pain: a review of safety data from randomized controlled trials conducted in Japan and in the west. Drug Safety. 2012;35(10):793-806.

97. Tzellos TG, Toulis KA, Goulis DG, et al. Gabapentin and pregabalin in the treatment of fibromyalgia: a systematic review and a meta-analysis. J Clin Pharm Ther. 2010;35(6):639-656.

98. Wustmann T, Piro J, Gutmann P. Metabolic considerations in a case of pregabalin-induced edema. Pharmacopsychiatry. 2009;42(2):75-76.

99. Krueger S, Lindstaedt M. Pregabalin and edema in young women suffering from premenstrual syndrome. Pharmacopsychiatry. 2010;43(5):202-203.

100. Guzelkucuk U, Duman I, Yilmaz B, Tan AK. Reversible postpregabalin peripheral edema in a spinal cord injury patient. Spinal Cord. 2012;50(6):472-473.

101. Gallagher R, Apostle N. Peripheral edema with pregabalin. CMAJ. [Epub November 5, 2012.]

102. Sendra JM, Junyent TT, Pellicer MJR. Pregabalin-induced hepatotoxicity. Ann Pharmacother. 2011;45(6):e32-e32.

103. Erdogan G, Ceyhan D, Gulec S. Possible heart failure associated with pregabalin use: case report. Agri. 2011;23(2):80-83. 
104. Aksakal E, Bakirci EM, Emet M, Uzkeser M. Complete atrioventricular block due to overdose of pregabalin. Am J Emerg Med. 2012;30(9).

105. Sjoberg G, Feychting K. Pregabalin Overdose in Adults and AdolescentsExperience in Sweden. Clin Toxicol. 2010;48(3):282-282.

106. Wood DM, Berry DJ, Glover G, Eastwood J, Dargan PI. Significant pregabalin toxicity managed with supportive care alone. J Med Toxicol. 2010;6(4):435-437.

107. Kavoussi R. Pregabalin: from molecule to medicine. Eur Neuropsychopharmacol. 2006;16:S128-S133.

108. Zacny JP, Paice JA, Coalson DW. Subjective, psychomotor, and physiological effects of pregabalin alone and in combination with oxycodone in healthy volunteers. Pharmacol Biochem Behav. 2012;100(3):560-565.

109. Grosshans M, Mutschler J, Hermann D, et al. Pregabalin abuse, dependence, and withdrawal: a case report. Am J Psychiat. 2010;167(7):869-869.

110. Filipetto FA, Zipp CP, Coren JS. Potential for pregabalin abuse or diversion after past drug-seeking behavior. J Am Osteopath Assoc. 2010;110(10):605-607.

111. Schwan S, Sundstrom A, Stjernberg E, Hallberg E, Hallberg P. A signal for an abuse liability for pregabalin-results from the Swedish spontaneous adverse drug reaction reporting system. Eur J Clin Pharmacol. 2010;66(9):947-953.

112. Schifano F, D’Offizi S, Piccione M, et al. Is there a recreational misuse potential for pregabalin? Analysis of anecdotal online reports in comparison with related gabapentin and clonazepam data. Psychother Psychosom. 2011;80(2):118-122.

113. Gahr M, Freudenmann R, Hiemke C, Kölle M, Schönfeldt-Lecuona C. Pregabalin abuse and dependence in Germany: results from a database query. Eur J Clin Pharmacol. 2013;69(6):1335-1342.

114. Oulis P, Konstantakopoulos G, Kouzoupis AV, et al. Pregabalin in the discontinuation of long-term benzodiazepines' use. Hum Psychopharmacol. 2008;23(4):337-340.

115. Oulis P, Masdrakis VG, Karakatsanis NA, et al. Pregabalin in the discontinuation of long-term benzodiazepine use: a case-series. Int Clin Psychopharm. 2008;23(2):110-112.
116. Oulis P, Nakkas G, Masdrakis VG. Pregabalin in zolpidem dependence and withdrawal. Clin Neuropharmacol. 2011;34(2):90-91.

117. Bobes J, Rubio G, Teran A, et al. Pregabalin for the discontinuation of long-term benzodiazepines use: an assessment of its effectiveness in daily clinical practice. Eur Psychiatry. 2012;27(4):301-307.

118. Hadley SJ, Mandel FS, Schweizer E. Switching from longterm benzodiazepine therapy to pregabalin in patients with generalized anxiety disorder: a double-blind, placebo-controlled trial. J Psychopharmacol. 2012;26(4):461-470.

119. Stopponi S, Somaini L, Cippitelli A, et al. Pregabalin reduces alcohol drinking and relapse to alcohol seeking in the rat. Psychopharmacology (Berl). 2012;220(1):87-96.

120. Becker HC, Myrick H, Veatch LM. Pregabalin is effective against behavioral and electrographic seizures during alcohol withdrawal. Alcohol Alcohol. 2006;41(4):399-406.

121. Guglielmo R, Martinotti G, Clerici M, Janiri L. Pregabalin for alcohol dependence: a critical review of the literature. Adv Ther. 2012; 29(11):947-957.

122. Bandelow B, Zohar J, Hollander E, et al. World Federation of Societies of Biological Psychiatry (WFSBP) guidelines for the pharmacological treatment of anxiety, obsessive-compulsive and post-traumatic stress disorders - first revision. World J Biol Psychiatry. 2008;9(4): 248-312.

123. Baldwin DS, Allgulander C, Bandelow B, Ferre F, Pallanti S. An international survey of reported prescribing practice in the treatment of patients with generalised anxiety disorder. World J Biol Psychiatry. 2012;13(7):510-516.

124. Bandelow B, Sher L, Bunevicius R, et al; WFSBP Task Force on Mental Disorders in Primary Care; WFSBP Task Force on Anxiety Disorders, OCD and PTSD. Guidelines for the pharmacological treatment of anxiety disorders, obsessive-compulsive disorder and posttraumatic stress disorder in primary care. Int J Psychiatry Clin Pract. 2012;16(2):77-84.
Neuropsychiatric Disease and Treatment

\section{Publish your work in this journal}

Neuropsychiatric Disease and Treatment is an international, peerreviewed journal of clinical therapeutics and pharmacology focusing on concise rapid reporting of clinical or pre-clinical studies on a range of neuropsychiatric and neurological disorders. This journal is indexed on PubMed Central, the 'PsycINFO' database and CAS.

\section{Dovepress}

The manuscript management system is completely online and includes a very quick and fair peer-review system, which is all easy to use. Visit http://www.dovepress.com/testimonials.php to read real quotes from published authors. 